\title{
ALLOY ALUMINUM SOLIDIFICATION IN SQUARE SECTION
}

\section{SOLIDIFICACIÓN DE ALEACIÓN DE ALUMINIO EN CAVIDAD CUADRADA}

\author{
Carlos Hernán Salinas Lira ${ }^{1}$ \\ Recibido el 9 de mayo de 2005, aceptado el 6 de diciembre de 2005 \\ Received: May 9, 2005 Accepted: December 6, 2005
}

\begin{abstract}
RESUMEN
El objetivo del presente trabajo es desarrollar un modelo numérico para analizar el proceso de solidificación de metales considerando el fenómeno de convección natural en una aleación de aluminio en cavidad cuadrada. El medio físico es modelado como siendo fluido Newtoniano incompresible con propiedades térmicas isotrópicas, donde el calor es transferido por conducción y convección incluidos los fenómenos térmicos de cambio de fase. Esto último es modelado por una adaptación del Modelo de Entalpía, basado en una función de sólido, la cual libera el calor latente de acuerdo con la fracción de partículas de sólido generada. El modelo matemático contempla un sistema de ecuaciones diferenciales parciales no lineares de segundo orden: Momentum, continuidad, transferencia de calor y un conjunto de expresiones auxiliares que permiten cerrar el sistema y aplicar condiciones en contorno e interfaces. El modelo numérico es basado en el Método de Volúmenes Finitos, descrito en coordenadas curvilíneas y con esquema SIMPLER para acoplar presiones y velocidades. La estrategia de estudio comprende la simulación Bidimensional de aleación de aluminio (solidificación no isotérmica) en una cavidad cuadrada y un caso donde la conductividad del molde es considerada. Resultados transitorios son mostrados en la forma de líneas de corriente e isotermas comparados con datos de la literatura.
\end{abstract}

Palabras clave: Solidificación, convección, aluminio, cambio de fase, método de volúmenes finitos.

\begin{abstract}
The objective of the present work is to develop a numerical model to analyze the melting solidification process considering the natural convection phenomena to alloy aluminum in a square section. Physical medium is taken as incompressible Newtonian fluid with isotropy thermal properties where the heat is transferred by conduction and convection, included de thermal phase change phenomenon. The last one is modeled by the improvement procedure, called Enthalpy Model, based on the fraction solid function which liberates the latent heat according to fraction of solid particles generated using as parameter of the temperature level. The mathematical model is based on a non-linear second order differential partial equation system: Momentum, continuity, heat transfer equations and a set of auxiliary expressions with the purpose of equation system closure y applied the boundary and interface condition. The numerical model is based on Volume Finite Method in body fitted coordinates with a SIMPLER scheme to join pressure and velocities. The strategy study allows the two-dimensional solidification of alloy aluminum (Non-Isothermal Solidification) in square section and a case where de conductive effects of mould are considered. Unsteady steady results are showed in the way of streamlines and isotherms compared with available data.
\end{abstract}

Keywords: Solidification, Convection, Alloy Aluminum, Phase Change, Finite Volumes Method.

\section{INTRODUCTION}

This paper presents a study about solidification of and alloy aluminum that is known in the literature as solidliquid phase-change problem. Considerable research has been focused in this problem because of their scientific and practical significance in material processing [1]: Purification of metal, continuum casting, high temperature super conducting crystals, etc. The physical aspect of solidification process are reviewed by Beckermann and Viskanta [2] with a discussion of the principal topic in numerical simulation at macroscopic

\footnotetext{
${ }^{1}$ Departamento de Ingeniería Mecánica-Universidad del Bío-Bío, Av. Collao No 1202, Casilla 5-C, Concepción-Chile, CP: 4081112 casali@ubiobio.cl, fono: (56) (41) 731455/731499.
} 
scale, explicit modeled for average volume method are given. Application of future needs are discussed by Beckermann [3].

The classical analytical analysis for the solidification problem is so called Stephan Problem, which accept solution for few limited cases that are reviewed by Alexiades and Solomon [4]. The most general problem the numerical analysis has been used. The simplest problem is to study heat transfer by conduction without convection effects [5], [6]. Today with improvement of computational fluid dynamics has been possible to analyze the convection effects through direct numerical simulation using several finite methods [7]-[13].

The natural convection can explain some defects or lack of uniformity in alloys solidification such as the tendency to contract in the regions of more re circulation or the formation of convection chimneys associated to the concentration gradients [14]-[20]. A novel work for exploring process/property/microstructure relationships in polycrystal materials called Statistical learning techniques is presented by Sundararaghavan and Zabaras [21].

The historical of finite methods have two basic directions: The fixed grid methods are easier which are used principally by researchers who work with Finite Difference and Finite Volume techniques [22]. The second direction is multi domain method naturally preferred by investigation that used Finite Elements Analysis [23]. Adaptive grid techniques and explicitly determination of interface is required in last case. Furthermore, the most recent research using mixed numerical model like Average Volume Method or by explicit determination of interface using a fixed grid are presented [24]. Relative merit of fixed grid and multi domain method has been discussed in the literature [25], [26].

Of course, the simple domain solution in a fixed grid for any kind of numerical method is easier to work and save computer time. The problem with explicit determination of front tracking are convection effects of grid moving and high curvature of interface position which can produced instability in the numerical solution and introduced unnecessary errors. However the problem is not how to discrete the mathematical model, but how to simulate the latent heat liberation, that happened at micro scales, to produce desirable macroscopic physical effects. This specially import in mushy zone for non-isothermal solidification and capturing front tracking for isothermal solidification. For this instance the Enthalpy Method [27] gives same tools to work in simple and consistent way for macroscopic formulation.

In this work the improvement enthalpy method is used for modeling the interchange of latent heat where the sensible heat is increased by latent heat liberated according to a liquid-solid phase-change fraction as function of temperature. The domain is discrete in a fixed grid without explicit formulation for interface. The mushy zone is modeled by partial latent heat liberation and modification the viscosity according to an inverse relation of solid-fraction in the solid-liquid temperature range. Solid boundaries are fixed to finite volumes, which has temperature under solid temperature. Two dimension non-linear heat transfer, momentum and continuity equations form a second order non-linear partial differential system equation which is solved by numerical procedure using finite volume method with algorithms development by authors [28], [29]. For instance, two problems are solved: a) Non-isothermal solidification of alloy aluminum in square section, b) Non-isothermal solidification of alloy aluminum included the mould. Results are showed of unsteady isothermal and streamline previous grid size consistency analysis.

\section{THE PHYSICAL PROBLEMS}

The physical liquid-solid phase-change problem for alloy aluminum in square section studied are showed in the figure 1 with properties summarized in table 1 . The figure 1a shows a schematic view of alloy aluminum solidification in square section considering as boundary condition three adiabatic wall and fourth left vertical wall depending on of the kind of problems. The initial condition are the rest flow and temperature equal to 700 $\left[{ }^{\circ} \mathrm{C}\right]$ considering at left vertical wall an imposed cold temperature equal to $500\left[{ }^{\circ} \mathrm{C}\right]$.

Figure $1 \mathrm{~b}$ shows a schematic view liquid-solid phasechange problem of alloy aluminum in mould. Heat conduction is account by heat conduction coefficient equal to $1\left[\mathrm{~W} / \mathrm{m}^{\circ} \mathrm{C}\right]$ which is two orders minor than heat conduction of alloy aluminum equal to $100\left[\mathrm{~W} / \mathrm{m}^{\circ} \mathrm{C}\right]$. The initial conditions are the rest flow with temperature equal to $100\left[{ }^{\circ} \mathrm{C}\right]$ and $700\left[{ }^{\circ} \mathrm{C}\right]$ for mould and alloy aluminum respectively. The boundary conditions are imposed at external wall according to global convection heat transfer coefficient equal to $100\left[\mathrm{~W} / \mathrm{m}^{2 \circ} \mathrm{C}\right]$ at environment temperature equal to $25\left[{ }^{\circ} \mathrm{C}\right]$. 

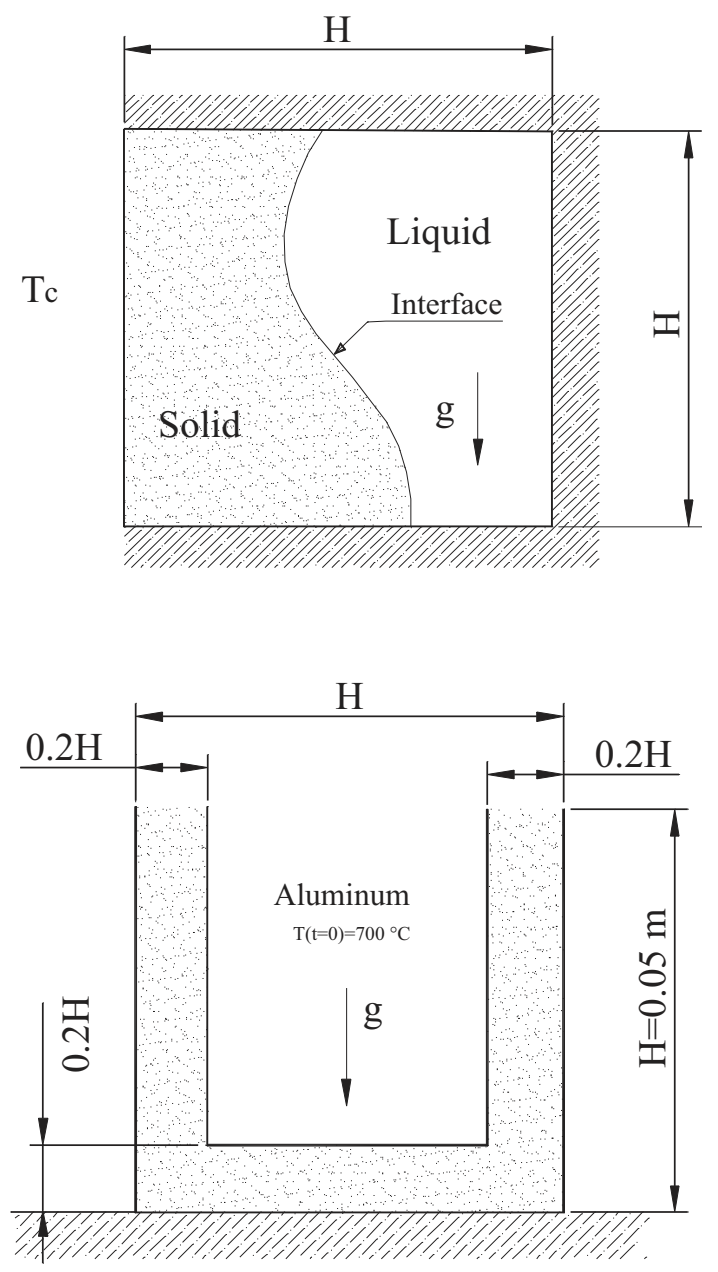

Fig. 1 Scheme of liquid-solid phase-change problems: a) Alloy aluminum in square section, b) alloy aluminum in mould.

Table 1 Physical properties of materials.

\begin{tabular}{|l|c|c|}
\hline Properties & Alloy Aluminum & Mould \\
\hline Density & $2500\left[\mathrm{~kg} / \mathrm{m}^{3}\right]$ & $1000\left[\mathrm{~kg} / \mathrm{m}^{3}\right]$ \\
\hline Conductivity & $100\left[\mathrm{~W} / \mathrm{m}^{\circ} \mathrm{C}\right]$ & $1.0\left[\mathrm{~W} / \mathrm{m}^{\circ} \mathrm{C}\right]$ \\
\hline Specific heat & $1000\left[\mathrm{~W} / \mathrm{Kg}{ }^{\circ} \mathrm{C}\right]$ & $1000\left[\mathrm{~W} / \mathrm{Kg}{ }^{\circ} \mathrm{C}\right]$ \\
\hline $\begin{array}{l}\text { Phase-change } \\
\text { enthalpy }\end{array}$ & $4.0^{*} 10^{5}\left[\mathrm{~J} / \mathrm{kg}{ }^{\circ} \mathrm{C}\right]$ & \\
\hline Solid Temp. & $550\left[{ }^{\circ} \mathrm{C}\right]$ & \\
\hline Liquid Temp. & $650\left[{ }^{\circ} \mathrm{C}\right]$ & \\
\hline Viscosity & $2.5^{*} 10^{-3}[\mathrm{~kg} / \mathrm{m} \mathrm{s}]$ & \\
\hline Thermal Exp. & $4.0^{*} 10^{-5}\left[1 /{ }^{\circ} \mathrm{C}\right]$ & \\
\hline
\end{tabular}

THE MATHEMATICAL MODEL

The mathematical model for two dimension liquid-solid phase-change problem, included the natural convection, in a simple domain solution considering alloys aluminum material is based on the Continuity, Linear Momentum and energy equations are presented by equations (1)-(4). It is supposed incompressible Newtonian fluid with properties constants (See table 1) except the density evaluated as linear function of temperature by Boussinesq approximation. The enthalpy method [27] is used to model the phase-change latent heat liberation by using a liquid-solid fraction function [30].

$$
\begin{aligned}
& \frac{\partial \mathrm{u}}{\partial \mathrm{x}}+\frac{\partial \mathrm{v}}{\partial \mathrm{y}}=0 \\
& \frac{\partial u}{\partial t}+u \frac{\partial u}{\partial x}+v \frac{\partial u}{\partial y}=-\frac{1}{\rho} \frac{\partial p}{\partial x}+\frac{\mu}{\rho}\left[\frac{\partial^{2} u}{\partial^{2} x}+\frac{\partial^{2} u}{\partial^{2} y}\right] \\
& \frac{\partial v}{\partial t}+u \frac{\partial v}{\partial x}+v \frac{\partial v}{\partial y}=-\frac{1}{\rho} \frac{\partial p}{\partial y}+\frac{\mu}{\rho}\left[\frac{\partial^{2} v}{\partial^{2} x}+\frac{\partial^{2} v}{\partial^{2} y}\right] \\
& +g \beta\left(T-T_{\text {ref }}\right) \\
& \rho\left(c_{p}+L \frac{\partial f_{p c}}{\partial T}\right)\left[\frac{\partial T}{\partial t}+u \frac{\partial T}{\partial x}+v \frac{\partial T}{\partial y}\right]=\kappa\left[\frac{\partial^{2} T}{\partial x^{2}}+\frac{\partial^{2} T}{\partial y^{2}}\right]
\end{aligned}
$$

Where: $\mathrm{u}, \mathrm{v}, \mathrm{p}$ and $\mathrm{T}$ are the dependent variables for the velocity components, pressure and temperatures respectively, and $\mu, \rho, \kappa, \mathrm{L}, \mathrm{f}_{\mathrm{pc}}$ and $\mathrm{c}_{\mathrm{p}}$ are the material properties of dynamic viscosity, density, thermal conductivity, phase-change enthalpy, liquid-solid fraction function and specific heat, respectively.

In the mould, the conduction is predicted by means of the linear heat diffusion equation, where the density $\rho_{m}$ and the thermal conductivity $\kappa_{\mathrm{m}}$ are considered constant.

$$
\rho_{\mathrm{m}} \mathrm{c}_{\mathrm{p}_{\mathrm{m}}} \frac{\partial \mathrm{T}}{\partial \mathrm{t}}=\frac{\partial}{\partial \mathrm{x}}\left(\kappa_{\mathrm{m}} \frac{\partial \mathrm{T}}{\partial \mathrm{x}}\right)+\frac{\partial}{\partial \mathrm{y}}\left(\kappa_{\mathrm{m}} \frac{\partial \mathrm{T}}{\partial \mathrm{y}}\right)
$$

The initial and boundary condition are given below for two physical problem studied. For all of them a linear 
liquid-solid fraction function is used with increased of viscosity in mushy zone according to inverse function of liquid-solid fraction value.

For solidification of alloy aluminum in Square Section.

Initial condition:

$$
\begin{aligned}
& \mathrm{u}=\mathrm{v}=0 \\
& \mathrm{~T}=700{ }^{\circ} \mathrm{C}
\end{aligned}
$$

Boundary condition:

$$
\begin{gathered}
u=0 ; v=0 \text { to } \mid \begin{array}{l}
x=0 \text { and } x=0.05 \mathrm{~m} \\
y=0 \text { and } y=0.05 \mathrm{~m}
\end{array} \\
\frac{\partial \mathrm{T}}{\partial \mathrm{y}}=0 \text { to } \mathrm{y}=0 \text { and } \mathrm{y}=0.05 \mathrm{~m} \\
\frac{\partial \mathrm{T}}{\partial \mathrm{x}}=0 \text { to } \mathrm{x}=0.05 \mathrm{~m} \\
\mathrm{~T}=500{ }^{0} \mathrm{C} \text { to } \mathrm{x}=0
\end{gathered}
$$

For solidification of alloy aluminum in mould.

Initial condition:

$$
\begin{aligned}
& \mathrm{u}=0 ; \mathrm{v}=0 \\
& \mathrm{~T}=700{ }^{0} \mathrm{C} \text { to } \text { Melt } \\
& \mathrm{T}=100{ }^{0} \mathrm{C} \text { to Mould }
\end{aligned}
$$

Boundary condition:

$$
\begin{aligned}
& \mathrm{u}=0 ; \mathrm{v}=0 \text { to } \mid \begin{array}{l}
\mathrm{x}=0.01,0.04 \mathrm{~m} ; 0.01 \leq \mathrm{y} \leq 0.05 \mathrm{~m} \\
\mathrm{y}=0.01 \mathrm{~m} ; 0.01 \leq \mathrm{x} \leq 0.04 \mathrm{~m}
\end{array} \\
& \frac{\partial \mathrm{u}}{\partial \mathrm{y}}=0 ; \mathrm{v}=0 \text { to } \mathrm{y}=0.05 \mathrm{~m} ; 0.01 \leq \mathrm{x} \leq 0.04 \mathrm{~m} \\
& \left.\frac{\partial \mathrm{T}}{\partial \mathrm{y}}\right|_{\mathrm{y}=0}=0 \text { to } 0.0 \leq \mathrm{x} \leq 0.05 \mathrm{~m} \\
& \left.\mathrm{k} \frac{\partial \mathrm{T}}{\partial \mathrm{x}}\right|_{\mathrm{x}=0,0.05 \mathrm{~m}}=-\mathrm{h}\left[\mathrm{T}-\mathrm{T}_{\text {env }}\right] \text { to } 0.0 \leq \mathrm{y} \leq 0.05 \mathrm{~m} \\
& \left.\mathrm{k} \frac{\partial \mathrm{T}}{\partial \mathrm{x}}\right|_{\mathrm{y}=0.05 \mathrm{~m}}=-\mathrm{h}\left[\mathrm{T}-\mathrm{T}_{\text {env }}\right] \text { to } 0.0 \leq \mathrm{x} \leq 0.05 \mathrm{~m}
\end{aligned}
$$

When the conductivity is space variable then is necessary an improvement procedure to model correctly the heat transfer conduction (solidification in mould) which is performed by introduction next effective conductivity obtain of conductivity boundary condition in interfaces [29].

$$
\begin{gathered}
\mathrm{T}_{\mathrm{w}}=\frac{\Delta \mathrm{n}_{\mathrm{P}} \mathrm{k}_{\mathrm{S}} \mathrm{T}_{\mathrm{S}}+\Delta \mathrm{n}_{\mathrm{S}} \mathrm{k}_{\mathrm{P}} \mathrm{T}_{\mathrm{P}}}{\Delta \mathrm{n}_{\mathrm{P}} \mathrm{k}_{\mathrm{S}}+\Delta \mathrm{n}_{\mathrm{S}} \mathrm{k}_{\mathrm{P}}} \\
\mathrm{k}_{\mathrm{e}}=\frac{\Delta \mathrm{n}_{\mathrm{S}} \mathrm{k}_{\mathrm{P}}}{\Delta \mathrm{n}_{\mathrm{P}} \mathrm{k}_{\mathrm{S}}+\Delta \mathrm{n}_{\mathrm{S}} \mathrm{k}_{\mathrm{P}}}
\end{gathered}
$$

When $\mathrm{k}_{\mathrm{e}}$ is used in equation (5), then the heat flow will be evaluated in a conservative form in each face of the finite volumes including the ones located in the interface between the aluminum and mould.

The equations (1)-(5) form a system of five partial differential equations that model fluid mechanics and heat transfer of liquid-solid phase-change process under initial and boundary condition described above. This mathematical model is solved in a numerical form as explained in the next section.

\section{NUMERICAL MODEL}

The computational fluid dynamics algorithm was developed by one of authors [28] and modified to include the calculation of heat transfer in Moraga and Salinas [29]. In this section the main aspect of the algorithms, particular values of parameters are given.

The algorithm is developed in body fitted coordinates system generated by a Poisson equation with the stretching function described in Thompson [31] and implemented in Salinas [28]. After transforming the system of equations the Finite Volumes Method (FVM) is applied to obtain the discrete system of equations. To couple the continuity and Navier-Stokes equations the SIMPLER algorithm [32] is used. A staggered grid is used to represent the variables considering $T, p$ and physical properties in the center of each control volume while the velocity components and heat fluxes are calculated in the faces of the finite volumes. The terms of diffusion (second order derivatives) and Laplacian operator are calculated through a central difference scheme, the convection terms (first order derivatives) are evaluated through the power law interpolation [32] and the transient terms are calculated in an implicit way by using a backwards difference procedure. The nonlinear system equation is linearized by using values of the properties obtained in the previous iteration and Crank-Nicolson procedure for the convection terms [33]. 
Afterwards the linear systems of equations are solved by the iterative Gauss-Seidel method with successive relaxation. Relaxation factors equals to $0.65,0.55$ and 0.55 for $\mathrm{p}, \mathrm{T}, \mathrm{u}$ and $\mathrm{v}$, respectively are used. Generally not more thanree SIMPLER cycles and around $10^{3}$ iterations for each linear system are adequate in order to obtain convergence with maximum local deviation for $\mathrm{u}, \mathrm{v}, \mathrm{p}$ and $\mathrm{T}$ equal to $7.0 \mathrm{E}-3 \%$.

\section{VALIDATIONS OF NUMERICAL CALCULATIONS}

The transient evolution of natural convection of air in a square cavity [34] was used to validate the fluid mechanics and heat transfer. The results for Rayleigh numbers equal to $10^{4}, 10^{5}$ and $10^{6}$ was presented in previous works [35].

A consistence analysis is performed to study convergence. For this case non-isothermal solidification problem is used showing results in the figures 2-4. In the figure 2 and figure 3 can see a good convergence in relation to grid size $40 \times 40$ in relation to coarse grid $20 \times 20$ and fine grid 60x60 when is analyzed local center vertical velocity and centerline temperature at indicated time. In transient temperature at center point, showed by figure 4 for several grid size, is observed a convergence to grid size $40 \times 40$ too which is very close to temperature curve obtained with grid size equal $60 \times 60$. This convergence study can be concluded that a grid size $60 \times 60$ is a good grid to be used.

\section{RESULTS}

After the consistency analysis was performed the prediction for natural convection and heat transfer for two liquid-solid phase-change problems was accomplished. For all problem a uniform grid size $60 \times 60$ with constant time step are used.

Unsteady results of Non-isothermal solidification in square section obtained by the present model are presented in figure 5 . It shows streamlines and isotherms for $\mathrm{Gr}=1.0 \mathrm{e} 7, \mathrm{Pr}=0.025, \mathrm{St}=0.5$ at $\mathrm{t}=10,40$ and $80 \mathrm{~s}$. It can be observed that fluid flow has a complex and strongly unsteady development with secondary vortex in upper region and right under corner for initial times (showing at=10 s). After that only one vortex is formed as showed in figure at $\mathrm{t}=40 \mathrm{~s}$ and $\mathrm{t}=80 \mathrm{~s}$. This results are very similar to the one presented by Cruchaga and Celentano (1997), Nevertheless in this work is not predicted the secondary vortex.
Numerical results of non-isothermal solidification in mould obtain by the present model are presented in figure 6. In this figure can be observed the streamline and isothermal for $\mathrm{Gr}=1.12 \mathrm{e} 6, \mathrm{Pr}=0.025$ at $\mathrm{t}=10,40$ and 100 $\mathrm{s}$ using time step equal $0.01 \mathrm{~s}$. The figure shows the transient fluid flow and heat transfer performed having symmetrical configuration with one vortex which has movement to upper caused by minor heat transfer in the mould than alloy aluminum material and buoyant force. The center of mushy zone (smallest temperature) has dawn movement to center melt. The numerical results in general do not have any singular performer.

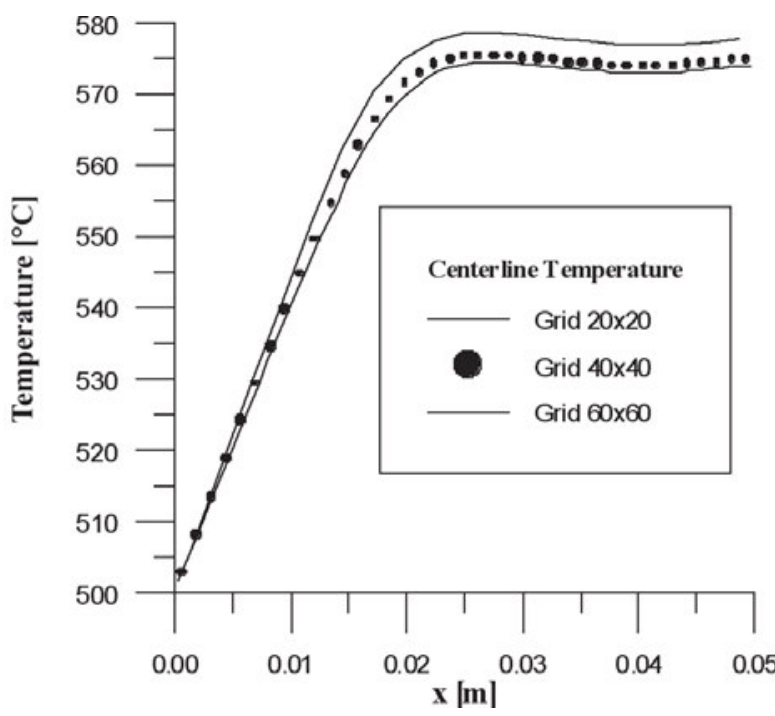

Fig. 2 Centerline temperature $\mathrm{v} / \mathrm{s}$ grid size at $\mathrm{t}=50 \mathrm{~s}$.

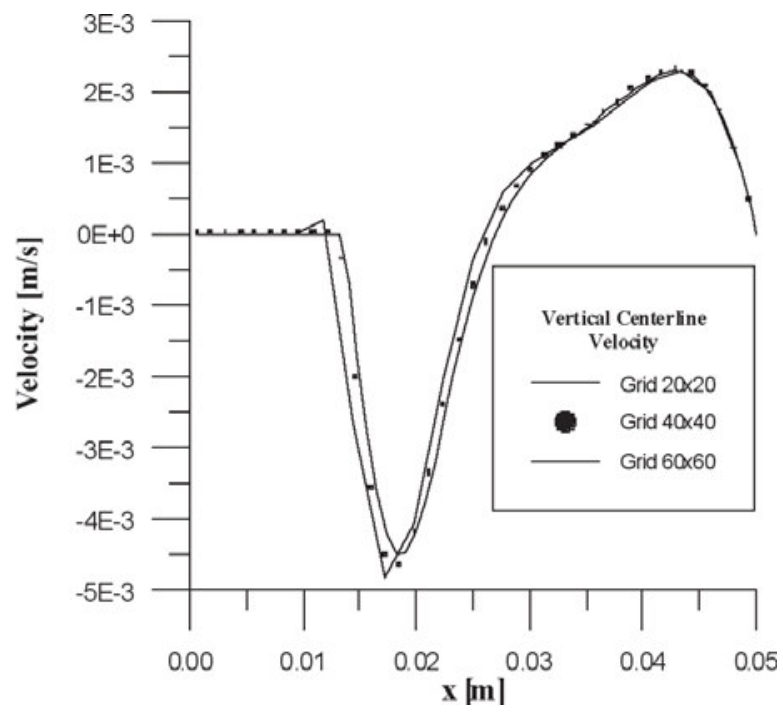

Fig. 3 Vertical centerline velocity $\mathrm{v} / \mathrm{s}$ grid size at $\mathrm{t}=50 \mathrm{~s}$. 


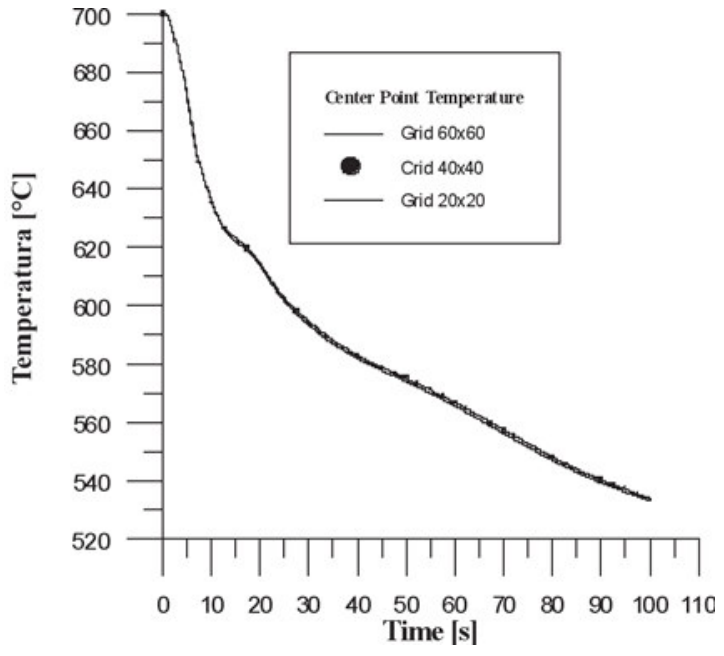

Fig. 4 Center time temperature v/s grid sizes.

\section{CONCLUSION}

A numerical model has been developed to solve the liquid-solid phase change problem for non-isothermal solidification process included the simple application where the mould was considered.

Numerical results of alloy aluminum solidification process in square section are similar to available numerical data. Nevertheless the same secondary vortex are no predicted in this work. Possibly the secondary vortex reported by another authors are artificially caused by numerical diffusion, which is major in Finite Element Method (reference numerical data) than Finite Volumes Method used in the present work.

When the mould has been included numerical results of solidification process has a good perform without irregularity. In this case the effect the buoyancy force are appreciated when vortex formed in the bottom has movement to upper caused by minor heat transfer in the mould than alloy aluminum material. At same time, the center of mushy zone has dawn movement to center melt.

The effect of different material mould over natural convection could be an interesting numerical experiment to performed in future researching.
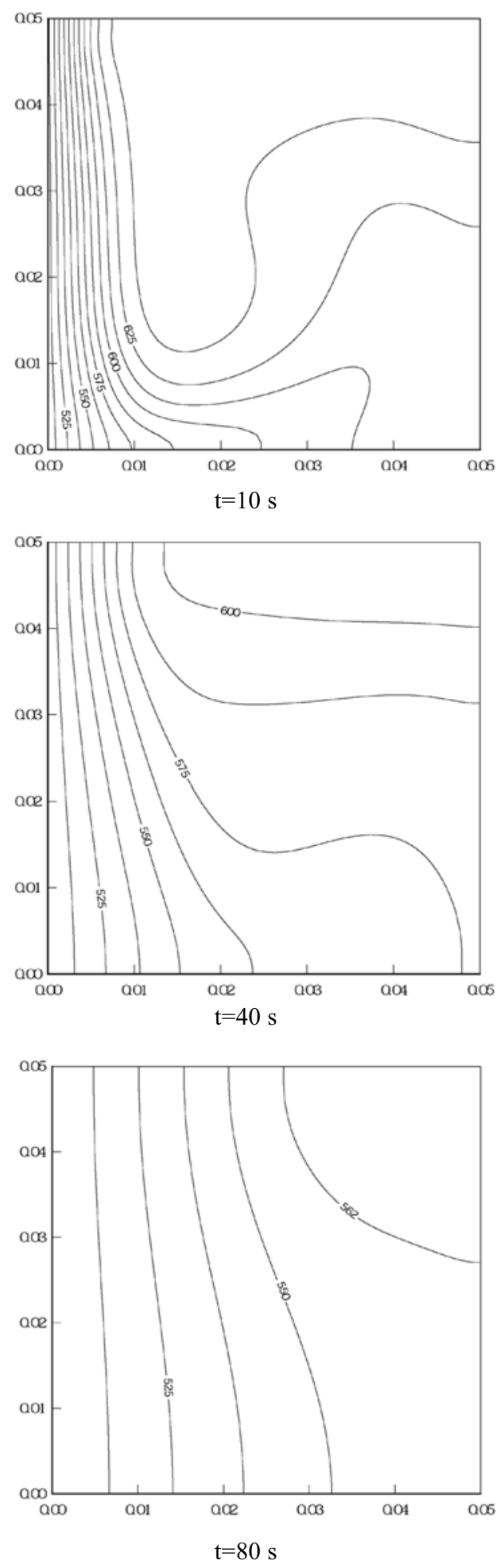

Fig. 5a Isotherms for alloy aluminum solidification $(\mathrm{Gr}=1.0 \mathrm{e} 7, \mathrm{t}=10,40$ y $80 \mathrm{~s}, \mathrm{Pr}=0.025, \mathrm{St}=0.5$, Grid size $60 \times 60, d t=0.01 \mathrm{~s}$ ) 

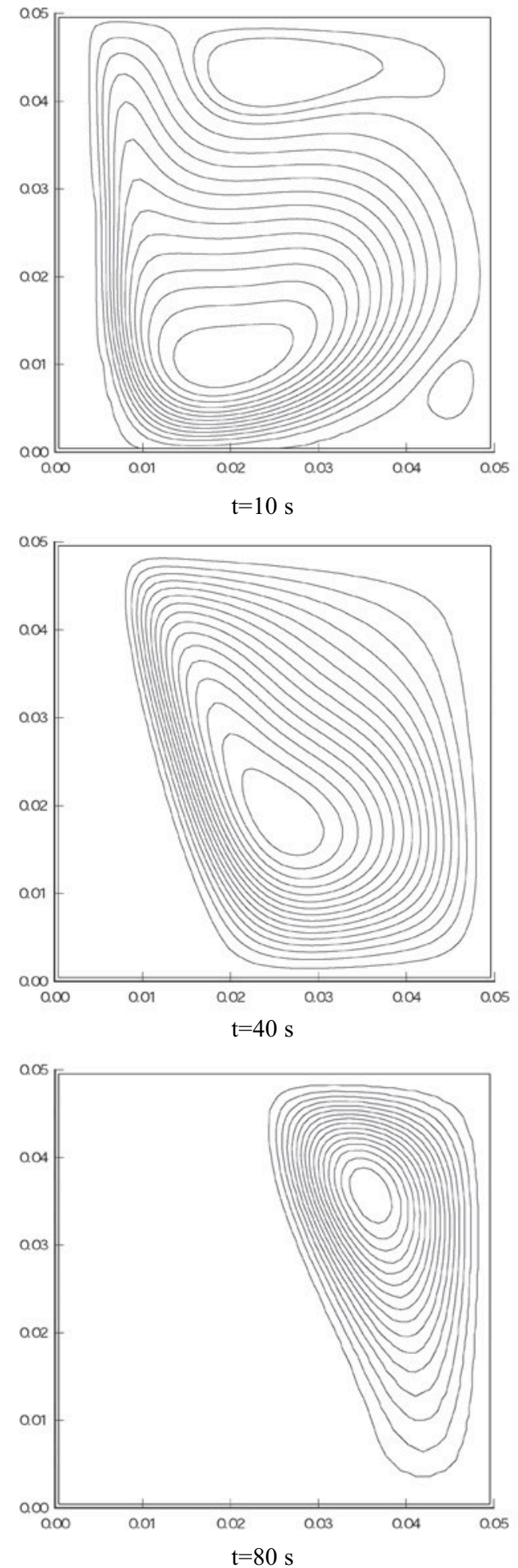

Fig. 5b Streamline for alloy aluminum solidification $(\mathrm{Gr}=1.0 \mathrm{e} 7, \mathrm{t}=10,40$ y $80 \mathrm{~s}, \mathrm{Pr}=0.025, \mathrm{St}=0.5$, Grid size $60 \times 60, \mathrm{dt}=0.01 \mathrm{~s}$ )
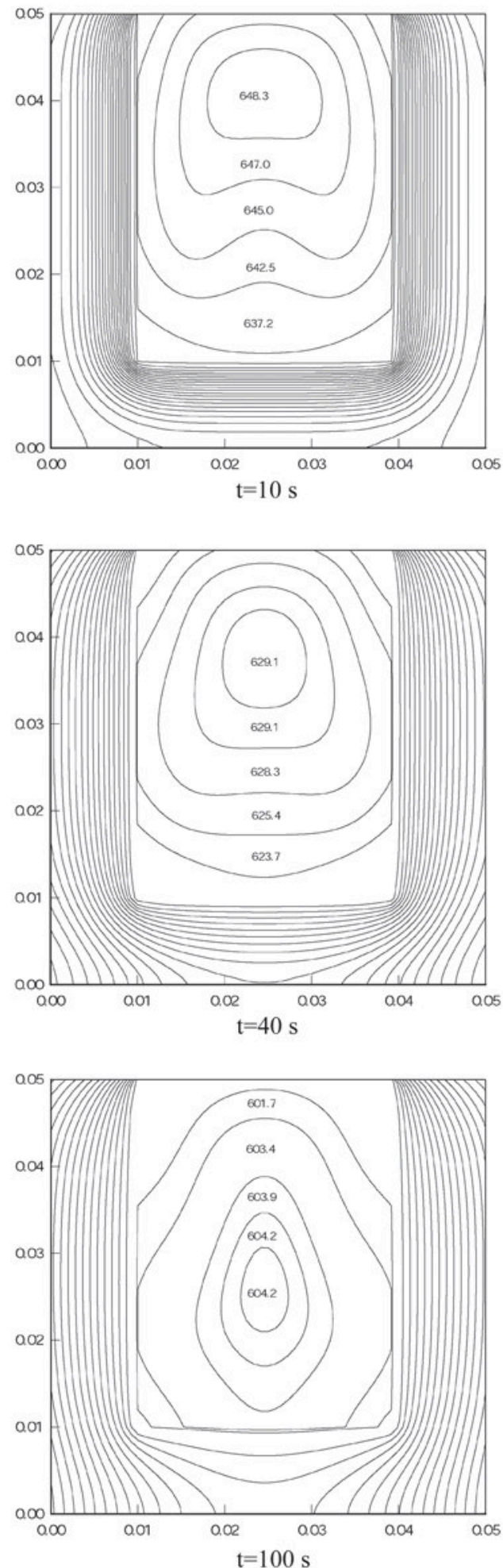

Fig. 6a Isotherms for alloy aluminum solidification in mould $(\mathrm{Gr}=5.12 \mathrm{e} 6, \mathrm{t}=10,40$ y $100 \mathrm{~s}, \mathrm{Pr}=0.025$, Grid size $60 \mathrm{x} 60, \mathrm{dt}=0.01 \mathrm{~s}$ ) 

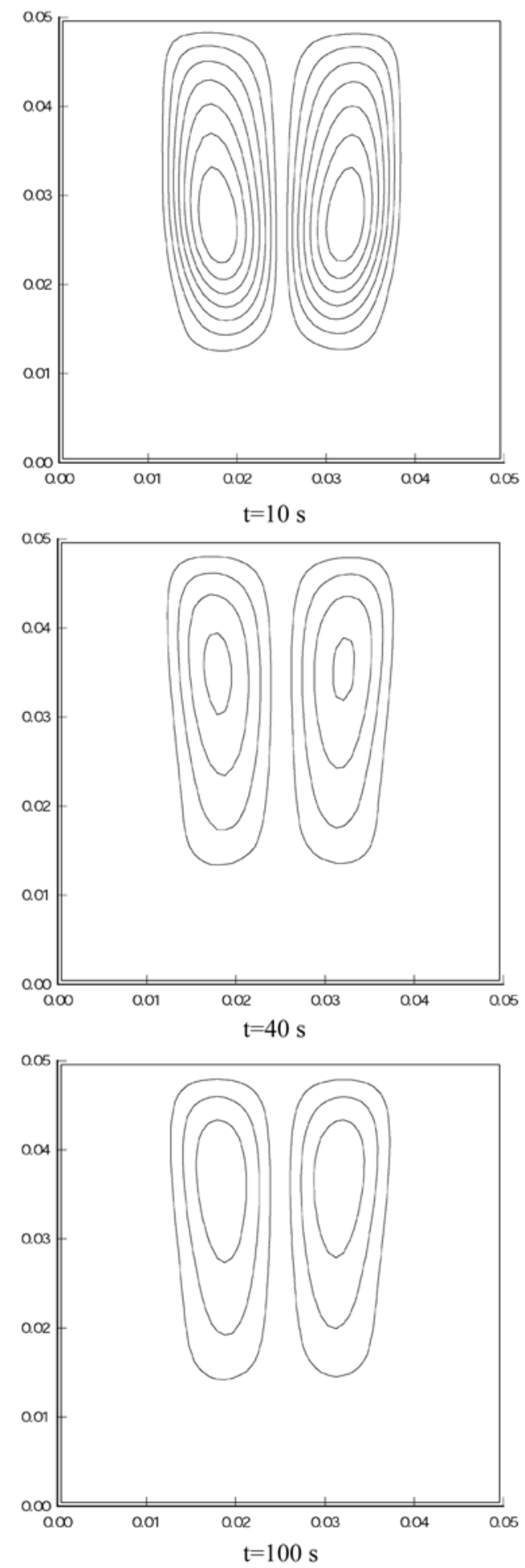

Fig. 6b Streamlines for alloy aluminum solidification in mould $(\mathrm{Gr}=5.12 \mathrm{e} 6, \mathrm{t}=10,40$ y $100 \mathrm{~s}, \mathrm{Pr}=0.025$, Grid size $60 \mathrm{x} 60, \mathrm{dt}=0.01 \mathrm{~s}$ )

\section{ACKNOWLEDGMENT}

Financial support for this study provided by Conicyt and Universidad del Bío-Bío through grant FONDECYT ${ }^{\circ}$ 1030209 and FPI $N^{\circ} 0152112$ respectively, is greatly appreciated.

\section{REFERENCES}

[1] P. Rohatgi. "Foundry Processing of Metal Matrix Composites". Modern Casting, pp. 47-50. April 1988.

[2] C. Beckermann and R. Viskanta. "Mathematical Modeling of Transport Phenomena During Alloy Solidification". Appl. Mech. Rev, Vol. 46, No 1, pp. 1-27. 1993.

[3] C. Beckermann. "Modelling of Macrosegregation: Applications and Future Needs", Int. Materials Reviews. Vol. 47, pp. 243-261. 2002.

[4] V. Alexiades and A.D. Solomon. "Mathematical Modeling of Melting and Freezing Processes". Chapter 2. Hemisphere Publishing Corporation. Washington. 1993.

[5] A. Lazaridis. "Numerical Solution of the Multidimensional Solidification (or Melting) Problems". Int. J. Heat Mass Transfer. Vol. 13, pp. 1459-1477. 1970.

[6] J.S. Hsiao. "An Efficient Algorithm for Finite Difference Analyses of Heat Transfer with Melting and Solidification". Numerical Heat Transfer. Vol 8, pp. 653-666. 1985.

[7] W. Kurz and D. Fisher. "Fundamentals of Solidification". Trans Tech Publications. Aedermannsdorf, Switzerland. 1998.

[8] M. Sparrow, S.V. Patankar, S. Ramadhyani. "Analysis of Melting in Presence of natural Convection in the Melt Region". ASME J. Heat Transfer. Vol. 99, pp. 520-526. 1977.

[9] J. Ni and C. Beckermann. "A volume-averaged two-phase model for transport phenomena during solidification". Metallurgical Transactions B. 22B, pp. 349-361. 1991. 
[10] R. Sampath and N. Zabaras. "An object oriented implementation of a front tracking finite element method for directional solidification process". Int. J. Numer. Meth. Engng. 44, pp. 1227-1265. 1999.

[11] D. Samanta and N. Zabaras. "Numerical study of macrosegregation in aluminum alloys solidifying on uneven surfaces". International Journal of Heat and Mass Transfer. Vol. 48, pp. 4541-4556. 2005.

[12] N. Zabaras and D. Samanta. "A stabilized volume-averaging finite element method for flow in porous media and binary alloy solidification processes". Int. J. Numer. Meth. Engng. Vol. 60. $\mathrm{N}^{\mathrm{o}}$ 6, pp. 1103-1138. 2004.

[13] J.C. Ramirez and C. Beckermann. "Examination of Binary Alloy Free Dendritic Growth Theories with a Phase-Field Model". Acta Materialia. Vol. 53, pp. 1721-1736. 2005.

[14] N. Ahmad, H. Combeaau, J.L. Desbiolles, T. Jalanti, G. Lesoult, J. Rappaz M. Rappaz and C. Stomp. "Numerical Simulation of Macrosegregation: A Comparison between Finite Volume Method and Finite Element Method Predictions and a Comparison with Experiments". Metallurgical and Materials Transactions A. Vol. 29, pp. 617-630. February 1998.

[15] R. Sampath and N. Zabaras. "Numerical study of convection in the directional solidification of a binary alloy driven by the combined action of buoyancy, surface tension and electromagnetic forces". Journal of Computational Physics. Vol. 168, pp. 384-411. 2001.

[16] R.S. Rerko, H.C. Groh III and C. Beckermann. "Effect of Melt Convection and Solid Transport on Macrosegregation and Grain Structure in Equiaxed Al-Cu Alloys". Mat. Sci. Eng. A. Vol. 347, pp. 186-197. 2003.

[17] J.C. Heinrich and D.R. Poirier. "Convection modelling in directional solidification". Comptes Rendus Academie Sciences Serie I - Mechanique. Vol. 332, pp. 429-445. 2004.
[18] B. Ganapathysubramanian and N. Zabaras. "Control of solidification of nonconducting materials using tailored magnetic fields". Journal of Crystal Growth. Vol. 276/1-2,pp. 299-316, 2005.

[19] D. Samanta and N. Zabaras. "A coupled thermomechanical, thermal transport and segregation analysis of the solidification of aluminum alloys on molds of uneven topographies". Materials Science and Engineering A. Vol. 408, pp. 211-226. 2005.

[20] Y. Lu, C. Beckermann and J.C Ramirez. "ThreeDimensional Phase-Field Simulations of the Effect of Convection on Free Dendritic Growth". J. Crystal Growth. Vol. 2080, pp. 320-334. 2005.

[21] V. Sundararaghavan and N. Zabaras. "A data mining approach for the design of polycrystalline materials". Proceedings of EPD Congress 2005. San Francisco, California. February 13-17. 2005.

[22] F. Wolff and R. Viskanta. "Solidification of a Pure Metal at a Vertical Wall in the Presence of Liquid Superheat". Int. J. Heat Mass Transfer. Vol. 31. No 8, pp. 1735-1744. 1988.

[23] D.J. McDaniel and N. Zabaras. "A Least-squares Front-Tracking Finite Element Method Analysis of Phase Change with Natural Convection". Int. J. For Num. Methods in Engineering. Vol. 37, pp. 2755-2777. 1994.

[24] C.K. Chun and S.O. Park. "A Fixed Grid FiniteDifference Method for Phase-Change Problems". Numerical Heat Transfer. Part B, Vol. 38, pp. 5973. 1999.

[25] M. Salcudean and Z. Aduallah. "On the Numerical Modeling of Heat Transfer During Solidification Processes". Int. J. Numer. Methods Engineering. Vol. 25, pp. 445-473. 1988.

[26] M. Lacroix and V.R. Voller. "Finite Difference Solution of Solidification Phase Change Problems: Transformed versus Fixed Grids". Numerical Heat Transfer. Part B, Vol. 17, pp. 2541. 1990. 
[27] C.R. Swaminathan and V.R. Voller. "On the Enthalpy Method". Int. J. of Num. Heat Fluid Flow. Vol. 3, pp. 233-244. 1993.

[28] C.H. Salinas. "Modelação de Escoamentos Tridimensionais em Geometrias Complexas". D. Sc. Thesis. COPPE/PENO. UFRJ. Rio de Janeiro, Brasil. 1996.

[29] N.O. Moraga and C. H. Salinas. "A Numerical Model for Heat and Fluid Flow in Food Freezing". Numerical Heat Transfer". Part A. Vol. 35, pp. 495-518. 1999.

[30] W.Y. Raw and S.L. Lee. "Application of Weighting Function Scheme on ConvectionConduction Phase Change Problems". Int. J. Heat Mass Transfer. Vol. 34, No 6, pp. 1503-1513. 1991.

[31] J.F. Thompson, A. Warsi and C.W. Mastin. "Numerical Grid Generation". Elsevier Science. Publishing. 1985.
[32] L. Lapidus and G.F. Pinder. "Numerical Solution of Partial Differential Equations in Science and Engineering”. John Wiley \& Sons. Inc. 1982.

[33] S.V. Patankar. "Numerical Heat Transfer and Fluid Flow". Hemisphere Publishing Corporation, Washington, DC. 1980.

[34] B.V.K. Satya Sai and K.N. Seetharamu. "Solution of Transient Laminar Natural Convection in a Square Cavity by an Explicit Finite Element Scheme". Numerical Heat Transfer. Part A. Vol. 25, pp. 593-609. 1994.

[35] N.O. Moraga and C. H. Salinas. "Numerical Study of Unsteady 2d Natural Convection and Solidification of a Food Inside a Freezing Chamber". Numerical Heat Transfer. Part A. Vol. 37: pp. 755-777. 2000.

[36] M. Cruchaga and D. Celentano. "Thermally Coupled Incompressible Flow Formulation With Phase-Change Effects". Tenth International Conference on Thermal Problem. U.K. 1997. 